\title{
Contributory Influence of Drill Cuttings on Equivalent Circulation Density Model in Deviated Wellbores
}

\author{
Anthony Kerunwa \\ Department of Petroleum Engineering, Federal University of Technology, Owerri, Nigeria \\ Email address: \\ anthonykerunwa@rocketmail.com \\ To cite this article: \\ Anthony Kerunwa. Contributory Influence of Drill Cuttings on Equivalent Circulation Density Model in Deviated Wellbores. International \\ Journal of Oil, Gas and Coal Engineering. Vol. 8, No. 4, 2020, pp. 82-90. doi: 10.11648/j.ogce.20200804.12
}

Received: July 18, 2020; Accepted: August 10, 2020; Published: August 27, 2020

\begin{abstract}
The estimation of equivalent circulation density (ECD) in oil well drilling and completion is rather of crucial importance and much care must be given in its calculation. This is because ECD being so sensitive, errors in its value estimation could lead to severe drilling and completion problems like kicks, loss circulation etc. especially when drilling in horizontal well sections, deepwater, depleted reservoirs, and wells with narrow pressure window. Traditional ECD calculation have only focused on the annular frictional pressure loss (AFPL) as the only contributory pressure loss (PL) in the ECD calculations, and most literatures have given more attention to this concept. Other factors aside AFPL contributes to the total $\mathrm{PL}$ at the bottom of the wellbore and these affect the value of ECD during drilling and completion operations. One of these factors is PL due to drill cuttings in the wellbore. In this work, the additional effect of drill cuttings to the annular frictional loss (AFL) in the wellbore has been considered. Awah BX2 well in the Niger Delta was used as case study. The Awah BX2 well is a deviated well that starts its inclination at 5000ft depth and having a measured depth of $14000 \mathrm{ft}$. Mud of 8.8 ppg was used in the study. Matlab software was used in the model simulation. Emphasis was made on results from the mud with and without drill cuttings. Effects of ROP, mud flowrate, concentration of cuttings have been investigated to determine the ECD values and pressure losses in the wellbore. From the results, it was observed that the presence of cuttings in the mud increased pressure loss and hence the ECD. It was also observed from the analysis that increasing value of bit rate of penetration (ROP) increases the concentration of cuttings and hence the pressure loss and ECD for a particular mud flowrate but when the concentration of cuttings increases so much, the ROP decreased. Increase in mud flowrate decreases the effective solids density and hence decreases the ECD and pressure loss. The model utilized in the study more accurately predicts pressure losses and ECD than that traditionally used in ECD calculations.
\end{abstract}

Keywords: Well Drilling, Pressure Loss, Completion Operations, Drillpipe Rotation, Differential Sticking

\section{Introduction}

Drilling and completion management entails procedures to ensure safe drilling and completion operations. Many problems are encountered in wells during well operations which may translate to dangerous and costly scenarios. It becomes pertinent and a rule of thumb to properly plan the well before any operation commences. In well planning, the target of the operator is to safely and economically reach the target depth within the shortest possible time. A lot of problems may be encountered while trying to achieve this. One of these problems is that offered by the mud in its contact with the wellbore and other well elements such as casing, DP, DC and other drilling jewelries [1]. ECD results from the circulation of DM in the wellbore [2-3] during pumping operations. ECD is a measure of the ABHP that is exerted on the formation during any drilling, completion or workover operations. Accurate determination of ECD is only achieved by models and conducting a robust modelling of the wellbore system and understanding the various sources of PLs in the wellbore and annulus region [4]. This is because ECD is mostly more appreciated in the annulus and represents the energy required by the mud to flow to the surface carrying cuttings [5]. As the mud travels up to the surface, it comes in contact with the wellbore wall and the walls of either, the DP, DC, casing or other elements in the well. Shear forces which acts between the fluid and the outside of the pipe and borehole wall creates PLs [6]. The cuttings presence in the mud further aggravates the PLs in the 
annulus as the mud travels to the surface [7-8]. The combined effect of friction that exists between the mud, the borehole wall and pipe wall, and the cuttings presence in the mud results in higher pressure drops. Other than the drill cuttings, other parameters that may affect the total PL in the wellbore include DS rotation, surge and swab pressure, and acceleration pressure [9-10]. The drop in pressure estimation and drill cuttings concentration in AW are highly influenced by diverse drilling parameters which include fluid properties, cutting size, flow rate, density, eccentricity of hole-pipe, annular geometry and DP rotation. Many researchers have tried to estimate the drop in pressure in annulus with cuttings present, with and without DP rotation [11-12]. Yanghua and Gefei, (2012) worked on the impact of cuttings concentration on ECD during drilling. They compared ECD for the mud with cuttings and without cuttings. They observed that cuttings concentration affects the pressure and ECD in annulus. They concluded that cuttings concentration should be calculated to predict the actual ECD at bottom to prevent the loss of circulation, differential sticking and other hazard that may damage the wellbore [4]. Experiment carried out by Sorgun et al., (2011) which composed of horizontal and inclined flow loops of pipes showed that the cuttings presence in the wellbore increases the drop in pressure due to decreased flow area inside of the wellbore [13]. In various research works conducted by Ahmed et al., (2010); Ogunrinde and Dosunmu, (2012) revealed that increasing the mud flowrate causes a decrease in cuttings accumulation in the wellbore [14, 2]. Han et al., (2010) carried out an experimental study using CFD on cuttings transport in vertical as well as greatly deviated slim annular hole and the study result showed that pressure drop in a solid-liquid mixture flow increases with mixture flow rate, annular inclination and DP rotation speed [11]. According to Adari, et al., (2000) controlling cuttings transport practically is much dependent on the field conditions encountered. To ensure effective and efficient hole cleaning, transport of cuttings in the annulus usually are not affected by one parameter but a whole lot of parameters [15]. Despite several studies in the literature on ECD, no significant attention was paid on the influence of drill cuttings on ECD. Moreover, of the few researches in the literature, none has exactly given a definition under which accumulation of drilled cuttings reduces or increases ECD in deviated wellbores. In this study, the influence of drill cuttings on ECD in Deviated Wellbores was investigated using MATLAB software. Rheology test was carried out with the formulated DM to determine the rheological parameters. To gain deeper knowledge on the drill cuttings' impact on ECD, simulation was carried out on DM with cuttings and DM without cuttings on TVD and PLs.

\section{General Notion of ECD}

ECD represents the ABHP that is exerted on the formation during drilling or completion operations. It represents the sum of the ESD of the mud and the combined pressure drops experienced at the bottom of the wellbore. It is important to estimate the ECD as accurately as possible when drilling especially in horizontal well sections, deepwater drilling, drilling through depleted reservoirs, and wells with narrow pressure window. General ECD equation comprises the sum of the SMD and the AFL, back pressure, pipe movement including other sources of pressure contribution. These combined PLs are then converted to an equivalent density contribution and added to the SMD to get the ECD. The general equation to express ECD with the different pressure drops included is given below [16]:

$$
E C D=\rho_{m}+\frac{\sum_{i} \Delta P_{i}}{g z}
$$

Where: Pi is sum up of all the PLs, $g$ is acceleration due to gravity, $\mathrm{z}$ is the vertical depth

The equation is more convenient written in the form given below with all the sources duly outlined

$$
E C D=\rho_{m}+\frac{\Delta P_{f a}+\Delta P_{d c}+\Delta P_{r o t}+\Delta P_{s S}+\Delta P_{a c c}}{0.052 T V D}
$$

Where: $\Delta P_{f a}$ is the APL, $\Delta P_{d c}$ is drop in pressure drop due to drilling cuttings in the annulus, $\Delta P_{\text {rot }}$ is the drop in pressure due to DS rotation, $\Delta P_{s S}$ is the drop in pressure due to surge and swab, $\Delta P_{a c c}$ is the drop in pressure as a result of acceleration movements and $\rho_{m}$ is Density of mixture (Ibs/gal).

Some other factors such as the effects of increasing temperature with increasing depth, and increasing hydrostatic pressure with increasing depth, are ignored when calculating ECD since there effects are negligible [17].

\subsection{Explanation of the General ECD Equation}

The various components that contributes to the general ECD equation are outlined and discussed below.

\subsubsection{Annular Friction}

The PL caused by friction in the annulus is due to the motion of fluids against the wellbore wall and the pipe outside diameter. The friction between the fluid, wellbore and pipe wall creates additional pressure. When flow occurs in the annulus, shear forces acts between the fluid, pipe's outside and borehole wall. The frictional force acts along the interval of the annulus and increases the ECD due to friction presence. APL depends on many factors such as mud rheology and MW, wellbore geometry, DS rotation and hole cleaning.

\subsubsection{Effects of Cuttings}

The cuttings existence in the annulus provides additional pressure drop to that found in the annulus for an assumed cleaned hole. The concentration of cuttings in the wellbore becomes more relevant as the well becomes more deviated. The problem of concentration of cuttings in the wellbore is mostly pronounced in horizontal wells. In horizontal wells, suspended cuttings contribute additional pressure drop. Some of the cuttings settle, some are inside the mud flow, and some are lifted by lifting forces in the mud flow. Rotation of DS will influence this PL by changing how large the cutting beds 
will be [17]. In equations regarding the effects of cuttings on wellbore PLs, it is always pertinent to determine the cuttings carrying capacity and the concentration of cuttings. Generally, cuttings have higher density than most DFs. When heavy cuttings are suspended in the mud and transported by the DF, additional energy is used. Increased concentration of cuttings contributes to increase in FD and viscosity, and acts out as a PL that must be overcome by the mud pumps. Cuttings are mostly transported with lower velocity than the mud, which leads to cuttings accumulation and cuttings bedding, which further leads to PL increment. High effects of concentration of cuttings include well pack off, stuck pipe or no circulation.

\subsubsection{Swab and Surge Effects}

Swab and Surge come into discussion when considering pressure changes from tripping operations. Swab and surge are due to friction effect existing between the stationary DF and moving pipe. When running the DS into the borehole, mud is displaced by the DS. The displaced mud causes a change in annular flow velocity around the pipe, leading to an increased FPL. If the pipe is pulled out from the hole such as during tripping out, the DF will flow to replace the volume of DP removed from the hole. This will cause a decrease in annular velocity, and therefore a decrease in FPL. This reduction is referred to as swab. Similarly when pipe is ran in hole such as during tripping in, the PL increases and this is referred to as surge.

\subsubsection{Acceleration Effect}

There is acceleration during pipe movement which creates acceleration pressure. This is experienced during tripping operations and when gas kicks reaches the surface. Acceleration pressure further causes PLs which adds to the total PLs at the bottom of the wellbore [17].

\subsubsection{DS Rotation}

When the DS is rotated, the annular flow patterns will not be the same as that when there is no rotation. Rotation produces a tangential velocity along with the axial velocity from circulation. Because of the shear forces between the pipe and DF, a helical flow pattern could form in the annulus due to the tangential and axial velocities. These altered velocities from rotation can affect the FPL in different ways. DS rotation alters the BHFP. A lot of research work done in this area suggests that this effect is a positive change in the BHP while others claim this change is negative.

\subsection{Determination of ECD}

In reality the contributory factors to the ECD value in wellbore can be estimated using the general ECD equation given above. In the equation, FPL in the annulus has the most significance and impact of all the PLs. Owing to this, some models overwhelmingly assume that other PL components can be neglected by only selecting APL to be the determinant in calculating ECD from the equation. Thus, the ECD equation which has APL as the sole determining PLs is given below:

$$
E C D=\rho_{m}+\frac{\Delta P_{f a}}{0.052 T V D}
$$

The hydrostatic pressure $\left(p_{h}\right)$ due to the flow of mud at a depth is given by

$$
P_{h}=0.052 T V D \rho_{m}
$$

But in this work emphasis is made to the contribution of drilled cuttings to the ECD value. So the PL due to the concentration of cuttings in the wellbore needs be determined and added to the AFPL. Thus, ECD due to cuttings presence in the DM is given by:

$$
E C D=\rho_{m}+\frac{\Delta P_{f a}+\Delta P_{d c}}{0.052 T V D}
$$

\subsection{Determination of AFPLs}

The AFPL is calculated WRT each wellbore component e.g. DP, DC, casing etc. with the wellbore wall called the annular space. Flow regime governs the determination of AFPL. For Laminar flow the AFP drop for plastic fluids is given by the equation below

$$
\begin{gathered}
\frac{d P}{d L}=\frac{\mu_{p} v}{1500\left(d_{h}-d_{p}\right)^{2}}+\frac{Y_{b}}{300\left(d_{h}-d_{p}\right)} \\
\Delta P=L\left(\frac{\mu_{p} v}{1500\left(d_{h}-d_{p}\right)^{2}}+\frac{Y_{b}}{300\left(d_{h}-d_{p}\right)}\right)
\end{gathered}
$$

Where:

$\Delta \mathrm{P}=$ total AFP drop at that depth, psi

$\frac{\mathrm{dP}}{\mathrm{dL}}=$ frictional pressure drop per unit length, $\mathrm{psi} / \mathrm{ft}$

$\mu_{\mathrm{p}}=$ Plastic viscosity, $\mathrm{cp}, \quad \mathrm{v}=$ Velocity of the fluid, $\mathrm{ft} /$ sec., $\mathrm{Y}_{\mathrm{b}}=$ Yield point, $\mathrm{Lb} / 100 \mathrm{ft}$

$\mathrm{d}_{\mathrm{h}}=$ Hole diameter, $\mathrm{ft} \quad, \quad \mathrm{d}_{\mathrm{p}}=$

Drill string (DP, collars etc) outer diameter

The plastic viscosity is determined from rheological experimental readings as:

$$
\mu_{p}=\theta_{600}-\theta_{300}
$$

The yield point is determined using the equation (9) given below

$$
Y_{b}=\theta_{300}-\mu_{p}
$$

The velocity of the DM in the annulus is given by

$$
v=\frac{Q}{2.448\left(d_{h}^{2}-d_{p}^{2}\right)}
$$

Where: $\mathrm{Q}$ is the mud flowrate, gal/min

For turbulent flow, the AFP drop is calculated using the equation (11) below.

$$
\frac{d P}{d L}=\frac{f \rho v^{2}}{25.8\left(d_{h}-d_{p}\right)}
$$

Where: $\rho=$ the mud density, $p p g, \mathrm{f}=$ friction factor

The friction factor for turbulent flow is determined from the equation given below 


$$
f=\frac{a}{R e^{b}}
$$

The variables ' $a$ ' and ' $b$ ' are given in the equations below:

$$
\begin{aligned}
& a=\frac{\log n+3.93}{50} \\
& b=\frac{1.75-\log n}{7}
\end{aligned}
$$

Where ' $\mathrm{n}$ ' is the flow behavior index and ' $\mathrm{k}$ ' is the consistency factor given by:

$$
n=3.32 \log \left(\frac{\theta_{600}}{\theta_{300}}\right)
$$

$k=\frac{510 \theta_{300}}{511^{n}}$, with the unit of ' $\mathrm{k}$ ' in $\mathrm{cp}$

The Reynolds number $(\mathrm{R})$ is used to determine if the flow is in turbulent or laminar flow regime and $\mathrm{R}$ is given as:

$$
R=\frac{2970 \rho v\left(d_{h}-d_{p}\right)}{\mu_{p}}
$$

If $\mathrm{R}<2000$, then flow is laminar, if $\mathrm{R}>4000$, then flow is Turbulent and if $2000<\mathrm{R}<4000$, then flow is within the transition zone.

In this work, when flow is in transition zone, it is treated as though it is turbulent. The critical velocity defines the flow boundary, above the critical velocity, turbulent flow exists and below the critical velocity laminar flow exists. The critical velocity is calculated with the equation given below:

$$
v_{c}=\frac{1.08 \mu_{p}+1.08 \sqrt{\mu_{p}^{2}+9.3 \rho\left(d_{h}-d_{p}\right)^{2} Y_{b}}}{\rho\left(d_{h}-d_{p}\right)}
$$

\subsection{Depth Calculations}

To calculate TVD from MD the equations below are used

$$
\begin{gathered}
R_{v}=\frac{180 \Delta M D}{\pi\left(I_{2}-I_{1}\right)} \\
T V D=R_{v}\left(\cos I_{1}-\cos _{2}\right)
\end{gathered}
$$

Where:

$R_{v}=$ radius of curvature, $f t, \mathrm{MD}=$ Measured depth, $\mathrm{ft}$, $I_{1}=$ Initial inclination, degrees

$I_{2}=$ Final inclination, degrees

\subsection{Calculation of Pressure Loss Due To Drill Cuttings in the Wellbore}

The equations necessary to calculate the PL due to concentration of cuttings in the wellbore are given as:

$$
C_{a}=\frac{(R O P) d_{b}^{2}}{\left(V_{a}-V_{s}\right)\left(d_{h}{ }^{2}-d_{p}{ }^{2}\right)}
$$

Where: Va is the annular velocity in $\mathrm{ft} / \mathrm{sec}$ and $\mathrm{Vs}$ is the slip velocity in $\mathrm{ft} / \mathrm{sec}$

The slip velocity is calculated thus: For turbulent flow i.e. particle Reynolds number (Rp), Rp $>2000$ and drag coefficient $\left(\mathrm{C}_{\mathrm{d}}\right)=1.5$

$$
V_{s}=92.4 \sqrt{\frac{d_{s}\left(\rho_{c}-\rho_{f}\right)}{c_{d} \rho_{f}}}
$$

With Rp given by:

$$
R_{p}=15.47 \frac{\rho_{f} V_{s} d_{s}}{\mu_{a}}
$$

For $3<\mathrm{Rp}<300$ i.e. at intermediate flow regime, then the slip velocity in $\mathrm{ft} / \mathrm{sec}$ is given by:

$$
V_{s}=\frac{175 d_{s}\left(\rho_{c}-\rho_{f}\right)^{0.667}}{\mu_{a}^{0.333} \rho_{f}^{0.333}}
$$

But for laminar flow, i.e. $\mathrm{Rp}<3$, then the slip velocity is given as:

$$
V_{s}=4980 d_{s}^{2} \frac{\left(\rho_{c}-\rho_{f}\right)}{\mu_{a}}
$$

The apparent Viscosity is given by:

$$
\mu_{a}=\left[\left(\frac{2.4 v_{a}}{d_{h}-d_{p}}\right)\left(\frac{2 n+1}{3 n}\right)\right]^{2} \frac{200 k\left(d_{h}-d_{p}\right)}{v_{a}}
$$

Then the PL due to concentration of cuttings for a concentric annulus is given as:

$$
\Delta P_{c}=0.052 x \operatorname{TVD} x\left(\rho_{c}-\rho_{f}\right) C_{a}
$$

Thus, the ECD due to concentration of cuttings is given by:

$$
E C D=\rho_{m}+\frac{\Delta P_{f a}+\Delta P_{d c+\Delta P_{c}}}{0.052 T V D}
$$

The new hydrostatic pressure in the wellbore at a specific depth due to the presence of drill cuttings in the mud is given by:

$$
P_{h c}=0.052 T V D \rho_{m}+0.052 T V D\left(\rho_{c}-\rho_{m}\right) C_{a}
$$

And the effective density of the mud mixture due to the presence of drill cuttings is given as:

$$
\rho_{e}=\rho_{m}\left(1-C_{a}\right)+\rho_{c} C_{a}
$$

\section{Experiment, Parameters and Simulation}

\subsection{Formulation of Drilling Mud (DM)}

WBDM was formulated with PAC-R, bentonite as viscosifier, barite and other additives in various amounts as depicted in table 1 .

Table 1. Composition of WBDM sample.

\begin{tabular}{ll}
\hline Addictives & Sample A \\
\hline Water $(\mathrm{ml})$ & 322 \\
Caustic soda $(\mathrm{g})$ & 0.25 \\
Soda ash $(\mathrm{g})$ & 0.25 \\
Bentonite $(\mathrm{g})$ & 10 \\
Potassium chloride $(\mathrm{g})$ & 28 \\
Pac r $(\mathrm{g})$ & 2.0 \\
\hline
\end{tabular}




\begin{tabular}{ll}
\hline Addictives & Sample A \\
\hline Barite $(\mathrm{g})$ & 77 \\
\hline
\end{tabular}

\subsection{Mud Sample Mixing Procedure}

Drilled water measuring $322 \mathrm{mls}$ and soda ash addition of $0.25 \mathrm{~g}$ was made for water pre-treatment in other to get any hardness removed. Addition of bentonite of $10 \mathrm{~g}$ was made to the water which has been treated with the slurry of bentonite sheared for 20 minutes, thereafter allowed for 10 hours to static yield. Then 10hours was allowed for Prehydration and the slurry of bentonite agitated with the addition of caustic soda of $0.25 \mathrm{~g}$ made to the slurry which was thoroughly mixed for 3 minutes. Addition of $\mathrm{KCL}$ of $28 \mathrm{~g}$ was as well made and again mixed for another 3 minutes. Thereafter, addition of Pac-R of $2 \mathrm{~g}$ was made and then thoroughly mixed for another 3 minutes. Barite addition of $77 \mathrm{~g}$ was made and then agitation allowed for 20minutes. Hamilton Beach mixer was utilized for the mixing at moderate speed and the total time of mixing stood at 30 minutes.

\subsection{Rheology Test}

Fann model 35 viscometer was utilized for mud rheological properties determination. Calibration of the viscometer was carried out before WBDM rheological properties were determined. Thermo-cup was utilized to heat mud sample to $180^{\circ} \mathrm{F}$ and at $180^{\circ} \mathrm{F}$ attainment; the nub of viscometer was placed at $600,300,200,100,6$ as well as $3 \mathrm{rpm}$ to obtain the rheological parameters as depicted in table 2. The reading of the dial was as well taken at defined intervals.

\subsection{Well Parameters Utilized for the Study}

The well parameter utilized for this study were collected from Awah BX2 well of the Niger delta and were utilized as fixed values employed for calculation of ECD. The parameters include - DP ID. DP OD, hole size, well depth (TVD), density of cuttings, drill cuttings' diameter and pump rate as depicted in table 2 .

Table 2. Input Experimental data for the study.

\begin{tabular}{ll}
\hline Activity/Component & Value \\
\hline Mud Experimental data & \\
600RPM & 54 \\
300RPM & 42 \\
200RPM & 37 \\
100RPM & 26 \\
6RPM & 17 \\
3RPM & 14 \\
Mud Flowrate, Q, gpm & 600 \\
Mud Density, ppg & 8.8 \\
PV, cp & 12 \\
YP, lb/100ft & 30 \\
\hline
\end{tabular}

Table 3. Input well data for the study.

\begin{tabular}{ll}
\hline Well Data & \\
\hline Total Depth, ft & 14000 \\
TVD, ft & 9000 \\
Hole size, in & $97 / 8$ \\
Casing size & 8.755 \\
DPOD. in & $41 / 2$ \\
DPID. in & 3.826 \\
DCOD, in & $63 / 4$ \\
DCOD, in & $21 / 4$ \\
Bit size, in & $97 / 8$ \\
Hole inclination $\left(^{\circ}\right)$ & $0,15,30$ \\
Density of cuttings, ppg & 21.6 \\
Diameter of cuttings, in & 0.25 \\
\hline
\end{tabular}

\subsection{Simulation}

The simulation was conducted using Matlab R2014b software. MATLAB has been known as high-performance language mainly for technical computation. It integrates visualization computation* $\mathrm{n}$ as well as programming in environment that is easy-to-use where problems with their solutions are usually expressed in much known mathematical notations. Matlab software calculator called ECDcuttings.m was developed to enable quick calculation of the ECD values in real-time using a user-friendly calculator format program.

\section{Results and Discussions}

\subsection{Effect of ECD on Flowrate}

Figure 1 depicts ECD vs Mud flowrate at various ROP. The concentration of cuttings is influenced by the bit ROP. When the bit ROP is zero, then there are no cuttings in the mud and the mud system is treated as that "without cuttings. We investigated the relationship between ECD and mud flow rate with and without the cuttings presence in the mud. Increasing the mud flowrate increases the ECD value and influenced by flow regime. If the flow regime is laminar there is no eddies created. The presence of turbulent flow may further alter the expected increase in ECD profile due to mud flowrate increase. From, figure 1, increasing the ROP increases the ECD for a particular mud flowrate. If the hole cleaning is poor, this will cause the ECD to increase the more and the formation broken leading to mud losses. Increasing the ROP entails the presence of more cuttings in the mud which leads to higher effective solids density with higher pressure loss. Furthermore, from figure 1, without cuttings concentration (i.e $\mathrm{ROP}=0 \mathrm{ft} / \mathrm{hr}$ ), increasing the flowrate leads to increasing ECD until after $500 \mathrm{gpm}$ in which the ECD decreases at $600 \mathrm{gpm}$ and $700 \mathrm{gpm}$. But when cuttings is present (ie when $\mathrm{ROP} \neq 0 \mathrm{ft} / \mathrm{hr}$ ), increasing the flowrate leads to a decrease in the mud density for all flowrate values considered. Since the rheology of the DM plays a key role for transport of cuttings from the wellbore. Hole cleaning Optimization can be achieved through the utilization of DM with low value of gel strength as well as low viscosity. Irawan and Kinif, (2018) posited that if ECD remains a key limiting factor in certain scenarios like the case understudy, $\mathrm{DM}$ with high viscosity and high ratio of $\mathrm{YP} / \mathrm{PV}$ should be 
utilized; and also consideration should be given to thin fluids in regime of turbulent flow [18].

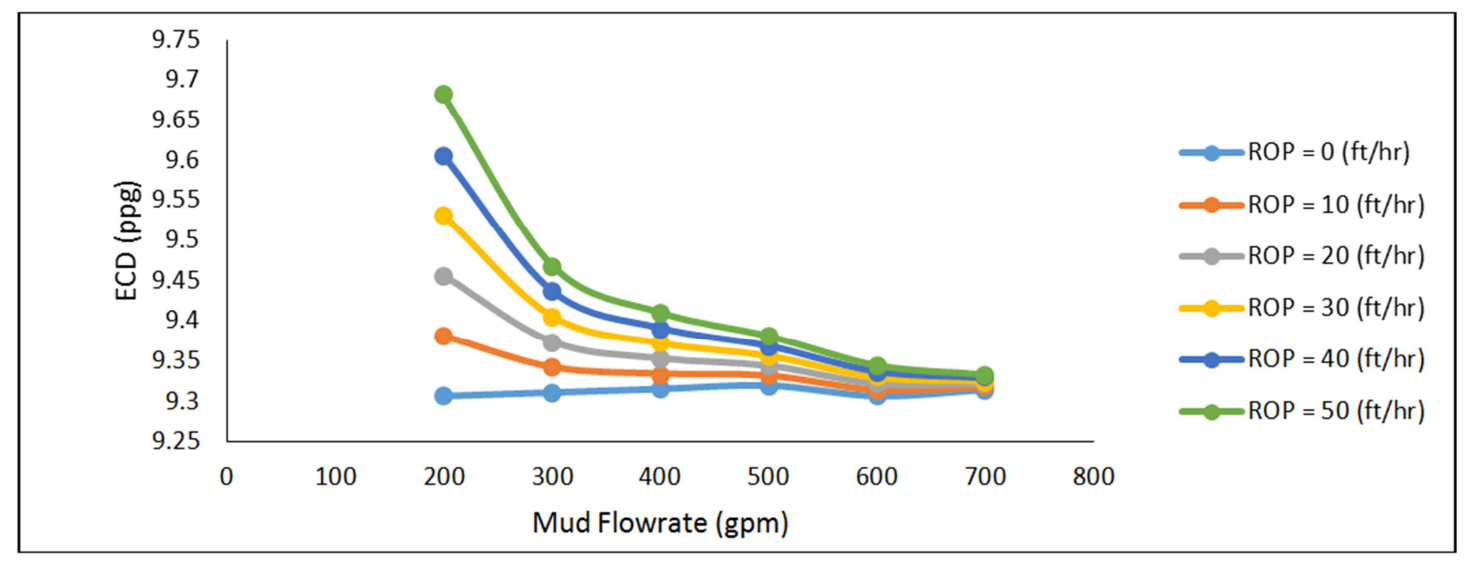

Figure 1. ECD vs Mud flowrate at different ROP.

\subsection{Effect of ECD on ROP}

Figure 2 depicts ECD vs ROP at different mud flowrate. From figure 2, ECD increases with increasing ROP, and decreases with increasing mud flowrate. This is because of the cuttings presence in the wellbore. Without cuttings presence, ECD increases with increasing mud flowrate.
Continuous concentration of cuttings in the DM system causes alteration of the DM properties. Irawan and Kinif, (2018) again posited that when the DM properties are altered, there is the tendency of lowering the drilling performance and if circulation of concentrated cuttings in the wellbore occurs up the annulus, the differential pressure is increased and this again slows down drilling [18].

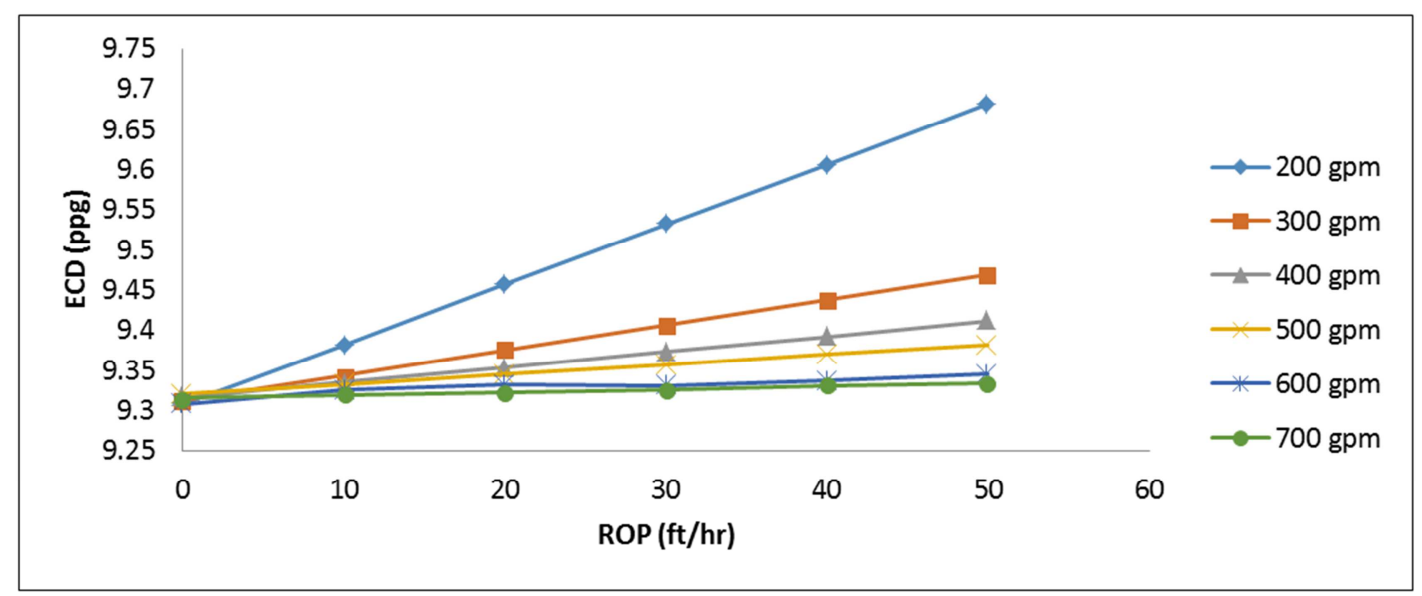

Figure 2. ECD at bit vs ROP at different mud flowrate.

\subsection{Effect of Concentration of Cuttings on ROP}

Figure 3 depicts the concentration of cuttings vs ROP for different mud flowrate. From the figure, it can be observed that the concentration of cuttings increases with decreasing ROP irrespective of the mud flowrate though DMs with high mud flowrate had lower concentration of cuttings. This is because at higher mud flowrate, the cuttings do not settle but are intimately mixed in the mud such that their influence in the mud becomes less pronounced. Specification of DM properties greatly affected the consistency of ROP. Again concentration of cuttings caused alteration of the DM properties which also decreased ROP thus lowering drilling performance. Rheological properties AWA that of filtration becomes extremely difficult to manage when concentrations of cuttings are in excess. High concentration of cuttings in the DM causes a reduction in the ROP due to viscosity and mud density increase. When the mud density is high, the exerted pressure differential will also be high and decrease in ROP causes an increase in pressure differential. Irawan and Kinif, (2018) also averred that fast penetration is promoted by low viscosity DM due good scavenging involved with drilled cuttings. Even with the application of more WOB, a good RPM can with all comfort achieve the needed ROP while drilling a hole with mud properties that are contaminated causes a reduction in ROP in the long run. Mud Properties like YS, PV and gel strength indicates that though the properties possesses great impact on ROP, nevertheless not that significant, only APLs appeared to severely impact on the ROP which has a direct relationship with ECD [18]. 


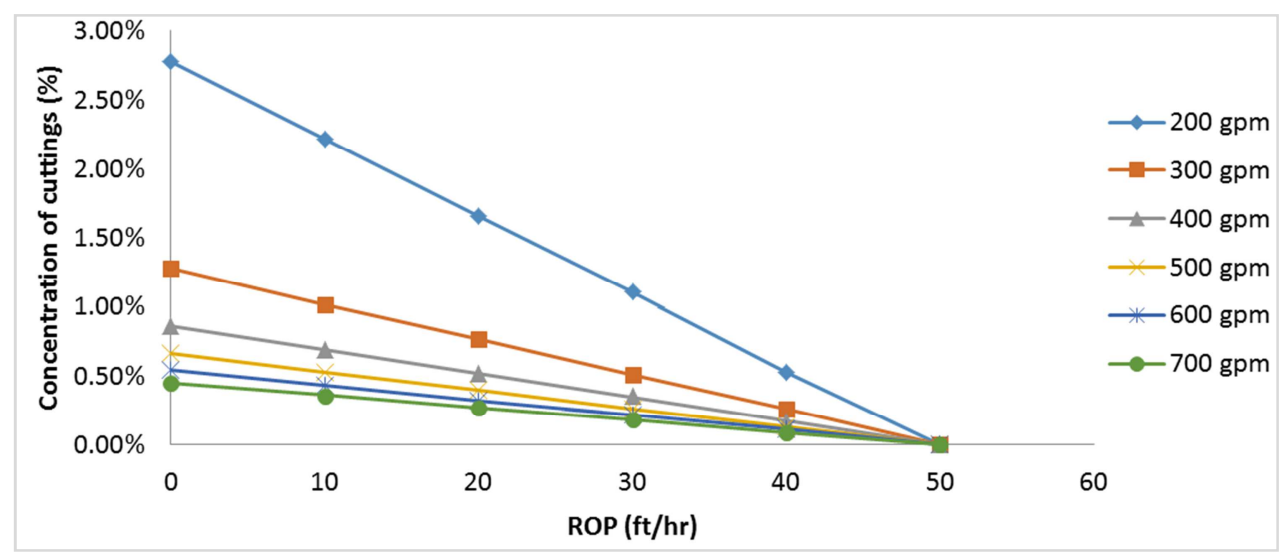

Figure 3. Concentration of cuttings vs ROP for different mud flowrate.

\subsection{Effect of TVD on ECD and Pressure Losses for Mud with and Without Cuttings}

Figure 4 depicts TVD vs ECD for mud with cuttings and mud without cuttings at of 300 gpm mud flowrate while Figure 5 depicts TVD vs Pressure losses for mud with and without cuttings. At the same flowrate. From figure 4, it can be observed that the mud with cuttings has higher ECD values along the TVD than the mud without cuttings. This is because, the vertical distance along which the DM will travel for it to get to reach the surface impacts on the pressure drop and subsequently on the ECD. The higher this distance, the greater the pressure drop that is exerted in the DM and as such the greater the ECD. Also the cuttings presence creates additional pressure drop that impacts on the ECD value. Thus, ECD is dependent on TVD and not on the measured depth which comprises horizontal sections of deviated wellbores. From figure 5, it can be observed that DM with cuttings has higher PLs along the TVD than the DM without cuttings. This is because the cuttings presence causes the absorption of more PLs by the formation. Since ECD is the summation of the SMD and total PLs, which is then converted to its equivalent of density, PLs therefore as well impacts on the ECD.

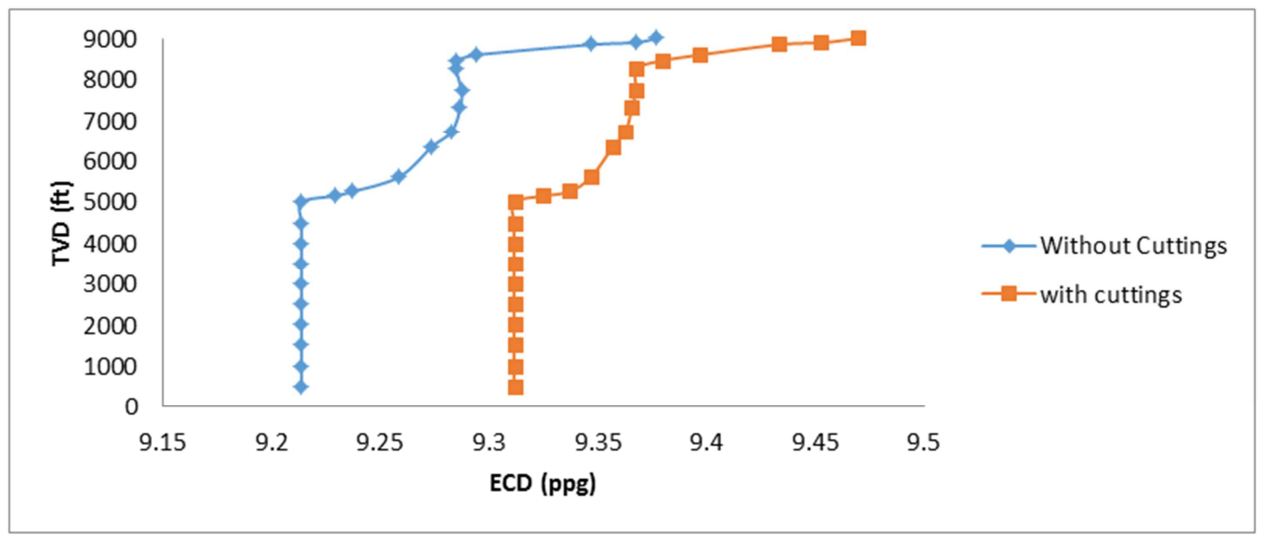

Figure 4. TVD vs ECD for mud with and without cuttings.

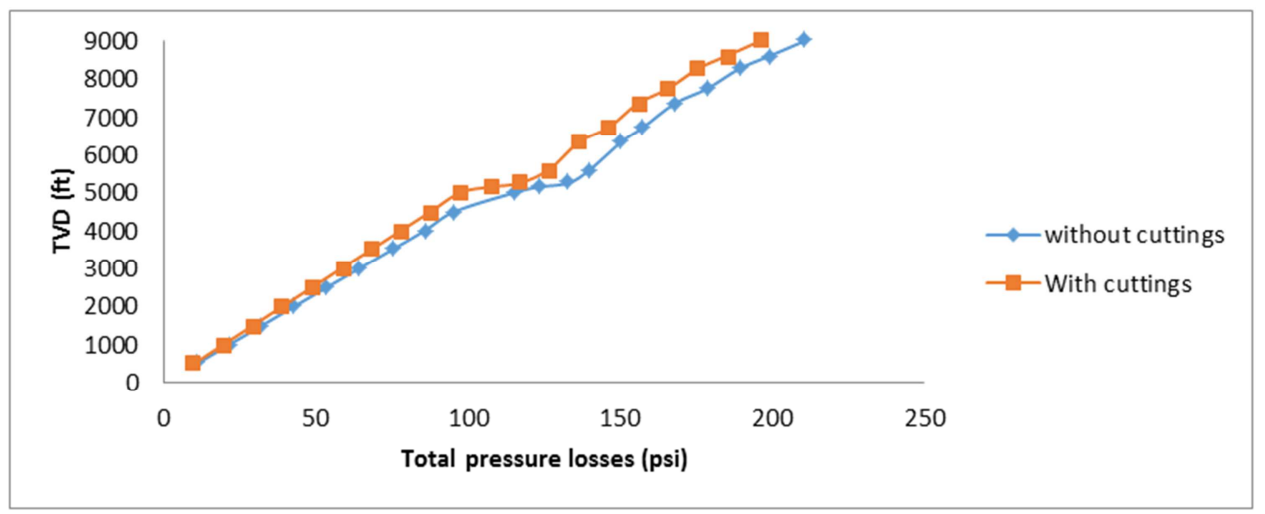

Figure 5. Depicts TVD vs Pressure losses for mud with and without cuttings. 


\section{Conclusion}

In this work, the effect of drill cuttings to wellbore pressure losses and ECD values has been extensively investigated. Effects of ROP, mud flowrate, concentration of cuttings have been investigated to determine the ECD values and pressure losses in the wellbore. From the work, the following conclusions are drawn:

1. Without cuttings, ECD tends to increase with increasing mud flowrate. But at a very high mud flowrate decreasing value of ECD may begin to be seen due to existence of flow turbulence.

2. With cutting in the mud, ECD will increase with increasing ROP and decrease with increasing mud flowrate. High mud flowrate decreases the effect of the cuttings in the mud. Thus, the effective mud weight due to cuttings decreases with increased mud flowrate.

3. Concentration of cuttings increases with decreasing ROP irrespective of the mud flowrate and DMs with high mud flowrate had lower concentration of cuttings

4. Mud with cuttings has higher ECD and pressure losses than mud without cuttings along the well depth. Thus, cuttings increase the ECD and pressure losses with regard to the true vertical depth.

It was also observed from the analysis that increasing value of bit ROP increases the concentration of cuttings and hence the pressure loss and ECD for a particular mud flowrate but when the concentration of cuttings increases so much, the ROP decreased. Increase in mud flowrate decreases the effective solids density and hence decreases the ECD and pressure loss. The model utilized in the study more accurately predicts PLs and ECD than that traditionally used in ECD calculations.

\section{Nomenclature}

ECD - Equivalent circulation density

Rp - Particle Reynolds number

AFPL - Annular frictional pressure loss

FPL - Frictional pressure loss

PL - Pressure loss

PLs - Pressure losses

AFP - Annular frictional pressure

DM - Drilling mud,

ABHP - Actual bottomhole pressure

DP - Drillpipe

DS - Drillstring

DC - Drillcollar

AW - Annular wellbore

ESD - Equivalent static density

SMD - Static mud density,

AFL - Annular friction loss

CFD - Computational fluid dynamics

DF - Drilling fluid

DFs - Drilling fluids

FD - Fluid density
BHFP - bottomhole flowing pressures

BHP - bottomhole pressures

WRT - With respect to

PAC-R - Poly Anionic Cellulose- Regular

TVD - True vertical depth

PV - Plastic Viscosity

RPM - Revolution per minutes

ROP - Rate of penetration

WOB - Weight on bit

YS - Yield stress

SC - Static conditions

\section{References}

[1] Cho, H., Shah, S. N., and Osisanya, S. O. (2001). Effects of fluid flow in a porous cuttings bed on cuttings transport efficiency and hydraulics. SPE 71374.

[2] Ogunrinde, J. O. and Dosunmu A. (2012). Hydraulics optimization for efficient hole cleaning in deviated and horizontal wells. SPE-162970-MS.

[3] Kerunwa A. and Gbaranbiri B. A. (2018): Evaluation of Local Viscosifiers as an Alternative to Conventional Pac-R. Advances in Petrol. Expl. Devept., Vol. 15 (1): 1-8.

[4] Yanghua X. and Gefei L., (2012). Impact of Cuttings Concentration on ECD during Drilling. Paper AADE-12FTCE-7.

[5] Ozbayoglu, M. E., Saasen A., Sorgun M. and Svanes K. (2010a). Critical fluid velocities for removing cuttings bed inside horizontal and deviated wells. Pet. Sci. Technol., 28: 594-602.

[6] Ozbayoglu E. M., Miska S. Z., Reed T. and Takach N (2003). Cutting Transport with Foam in Horizontal and Highly Inclined Wellbore. SPE 79856-MS.

[7] Fadairo A. S. A, Adekomaya O., Falode O. (2009). Effect of Drilling Cuttings Transport on Pressure Drop in a Flowing Well. SPE-125707-MS.

[8] Piroozian A., Ismail I., Yaacob Z., Babakhani P. and Ismail A. S. I. (2012). Impact of drilling fluid viscosity, velocity and hole inclination on cuttings transport in horizontal and highly deviated wells. J Petrol Explor. Prod Technol 2: 149-156.

[9] Ozbayoglu, M. E., Osgouei R. E., Ozbayoglu A. and Yuksel E. (2010b). Estimation of very-difficult-to-identify data for hole cleaning, cuttings transport and pressure drop estimation in directional and horizontal drilling. SPE-136304-MS.

[10] Mokhtari, M., Ermila M. A., Tutuncu A. N. and Karimi M. (2012). Computational modeling of drilling fluids dynamics in casing drilling. SPE-161301-MS.

[11] Han, S. K., Hwang Y. K., Woo N. S. and Kim Y. J. (2010). Solid-liquid hydrodynamics in a slim hole drilling annulus. J. Pet. Sci. Eng., 70: 308-319.

[12] Kummen, H. T. and Wold A. A. (2015). The effect of cuttings on annular pressure loss - An analysis of field data in the North Sea. Thesis submitted to the Dept. of Petrol. Engrg. and Applied Geophysics, Norwegian Uni. of Sci. and Tech. 
[13] Sorgun, M., Aydin I. and Ozbayoglu M. E. (2011). Friction factors for hydraulic calculations considering cuttings presence and pipe rotation in horizontal/highly-inclined wellbores. J. Pet. Sci. Eng., 78: 407-414.

[14] Ahmed, R., Sagheer M., Takach N., Majidi R. and. Yu M. (2010). Experimental studies on the effect of mechanical cleaning devices on annular cuttings concentration and applications for optimizing ERD systems. SPE-134269-MS.

[15] Adari, R. B., Miska S., Kuru E., Bern P. and Saasen A. (2000). Selecting drilling fluid properties and flow rates for effective hole cleaning in high-angle and horizontal wells. SPE-63050MS.
[16] Yoong W. L. S. (2012): Calculations of Equivalent Circulating Densities in Underbalanced Drilling Using Landmark WELLPLAN. Bachelor's Project, Universiti Teknologi PETRONAS, Tronoh Perah.

[17] Skalle, P. (2010). Drilling Fluid Engineering. (C) 2010 Pål Skalle \& Ventus Publishing ApS, ISBN 978-87- 7681-552-3.

[18] Irawan S. and Kinif I. B. (2018): Solid Control System for Maximizing Drilling. Retrieved from https://www.intechopen.com/books/drilling/solid-controlsystem-for-maximizing-drilling. 